\title{
Compound-mode crack propagation law of PMMA semicircular- arch roadway specimens under impact loading
}

\author{
Chengxiao Li ${ }^{1}$ (i) $\cdot$ Dongming Guo ${ }^{1} \cdot$ Yuantong Zhang ${ }^{1} \cdot$ Chen $^{1}{ }^{1}$
}

Received: 3 February 2021 / Revised: 17 April 2021 / Accepted: 22 June 2021 / Published online: 14 July 2021

(C) The Author(s) 2021

\begin{abstract}
An underground roadway usually contains defects of various types, and when the roadway is subjected to external loading, the locations of those defects influence the roadway by differing degrees. In this study, to study how the locations of defects affect crack propagation in a roadway, specimens with tunnel-type voids were made using polymethyl methacrylate, and the stress wave produced by a bullet impacting an incident rod was used as the impact load. Meanwhile, the variations in crack speed, displacement, and dynamic stress intensity factor during crack propagation were obtained using an experimental system of digital laser dynamic caustics, and the commercial software ABAQUS was used for numerical simulations. From the experiments and numerical simulations, the crack propagation path was verified and the impact fracture behavior of a semicircular-arch roadway with different defect positions was presented. The results show that when the pre-fabricated crack is on the central axis of the sample, the crack propagation is purely mode I; when the pre-fabricated crack is $5 \mathrm{~mm}$ from the central axis, the crack propagation alternates between mode I and a mixture of modes I and II; when the pre-fabricated crack is at the edge of the semicircular-arch roadway, the crack propagation follows the I-II mixed mode.
\end{abstract}

Keywords Defect location - Dynamic caustics $\cdot$ Polymethyl methacrylate $\cdot$ ABAQUS $\cdot$ Semicircular-arch roadway

\section{Introduction}

Because of the increasing consumption of shallow coal in modern social development, the mining of coal resources has shifted gradually to deep underground spaces. An important part of coal mining are semicircular-arch roadways, which are surrounded by rock defects (e.g., cracks, holes) that affect the stability of the roadway structures during excavation or structural maintenance (Chen 2019; Pan et al. 2019). When the surrounding rock with defects is subjected to external dynamic loading (e.g., blasting, roof collapse, rock burst), the resulting shock waves cause further

\section{Chengxiao Li}

licx93@163.com

1 School of Mechanics and Civil Engineering, China University of Mining and Technology-Beijing, Beijing 100083, China cracking and expansion of the original defects in the rock mass. They even penetrate other defects around the rock mass, thereby destroying the local stability of the rock mass and, in serious cases, also the roadway. Under the action of impact dynamic loading, the path, speed, and stress intensity of a crack as it propagates are affected by its location. Therefore, it is of great practical importance to study different crack locations for the crack propagation process and related parameters in a semicircular-arch roadway.

How defects influence the dynamic fracturing of media is an issue of intense interest in fracture-mechanics research. Yang et al. (2014) studied how crack angle influenced crack propagation by using the impact of a drop hammer on a medium containing a pre-fabricated crack, and Yue et al. (2010) conducted a three-point bending experiment and studied crack propagation under impact loading when the loading direction and crack angle of the drop hammer were different. Wang et al. (2017a, b) studied 
how an empty hole affected crack movement in a polymethyl methacrylate (PMMA) specimen under impact loading. Li et al. (2009) studied how the fracture dip angle in three-dimensional space influenced the dynamic fracturing of a rock-like medium. Liu et al. (2020) studied how external impact on a PMMA specimen affected multi-crack propagation. Yao et al. $(2002,2003)$ studied the interaction and propagation of two parallel precast cracks under dynamic tensile loading.

Developments in numerical simulation provide a convenient and effective means of studying how defects influence the dynamic fracturing of media, and especially for predicting mixed-mode crack propagation. Guo et al. $(2015,2016)$ investigated how explosive loading influenced crack propagation in a roadway, and they obtained the law governing the evolution of the dynamic stress intensity factor (DSIF) of the crack tip that is consistent with the numerical simulation. Zhou et al. (2019a, b, 2020) tested a rock tunnel under heavy hammer impact and studied the variations of crack propagation velocity, path, and other parameters in the tunnel by using numerical simulation and strain gauges. However, the methods used in the above studies were split Hopkinson pressure bar (SHPB) combined with numerical simulation, explosion combined with caustics, and impact combined with caustics, but there have been relatively few studies of dynamic crack propagation under a uniform stress wave by the caustic method.

As is well known, PMMA has good brittle fracture performance under dynamic loading and excellent optical performance, and so it is often used as a rock-like material to study the dynamic fracture process of brittle materials (Goseki and Ishizone 2015; Xu et al. 2019; Rossmanith et al. 1997; Zhuang et al. 2014; Li et al. 2020). Herein, we combine digital laser dynamic caustics (DLDC) with a stress-wave loading system and use PMMA as the material medium to explore the propagation of pre-fabricated cracks at different positions under stress-wave loading. We also use the extended finite-element method of the commercial software ABAQUS to simulate the crack growth process, and we compare the test and simulation results.

\section{Test principle and system}

\subsection{Principle of caustics test method}

Manogg (1964) first proposed the experimental method of caustics to solve the problem of singularity in experiments, and the proposed method was used to experiment on crack propagation in a plate with micro-holes. Theocaris (1972) and Kalthoff (1986) then extended the method to dynamic fracture problems under different loads. Guan and Yang
(1983) and Wu and Yang (1984) first introduced the method of using caustics to study static fractures in China, and Yang et al. (2013) developed a new DLDC experimental system by combining a high-speed photography system and a laser system. On this basis, the caustics method has been used widely in the dynamic fracturing process of rocks (Yang et al. 2016; Wang et al. 2017a, b).

Before it is deformed, the solid test model has a uniform thickness. It deforms when it is subjected to an external load, and the thickness of the region near the internal singularity (the complex parameter space forms a self-intersecting Riemann surface, where the intersection point is a singularity) no longer remains uniform. Because the thickness of the model changes, when parallel light is incident perpendicular to the surface of the specimen, its refractive index also changes. Consequently, the reflected light and refracted light on the back surface of the model are no longer parallel, and a three-dimensional caustic surface forms in the air. As shown in Fig. 1, these reflected and refracted rays are projected on a parallel reference plane within a certain range from the model, and the cross section of the caustic surface is obtained. In Fig. 2, the red curves are the caustic diagrams of cracks of type I (Fig. 2a) and mixed type I-II (Fig. 2b) formed under the reflected tensile stress of the specimen, and the black area enclosed in the middle is the caustic spot.

For a point $T(x, y)$ on the specimen, there is a corresponding point $T^{\prime}\left(x^{\prime}, y^{\prime}\right)$ on the reference surface, and their relationship can be expressed as (Kalthoff et al. 1986)

$\vec{X}=\vec{x}+\vec{w}$,

where, $\vec{w}$ is the vector of the specimen deflected to the reference plane by the distance $Z_{0}$, which can be expressed as

$\vec{w}=-Z_{0} \operatorname{grad} \Delta s_{\mathrm{r}, \mathrm{t}}(x, y)$

here, $\Delta s_{\mathrm{r}, \mathrm{t}}$ refers to the variation of light passing through the specimen, which can be expressed as

$\Delta s_{\mathrm{r}, \mathrm{t}}=\varepsilon d c_{\mathrm{r}, \mathrm{t}}\left[\left(\sigma_{1}+\sigma_{2}\right) \pm \xi_{\mathrm{r}, \mathrm{t}}\left(\sigma_{1}-\sigma_{2}\right)\right]$

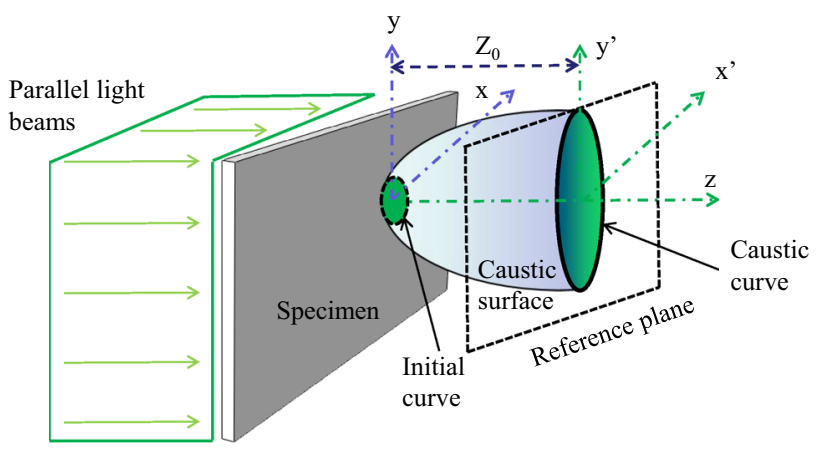

Fig. 1 Caustic principle 


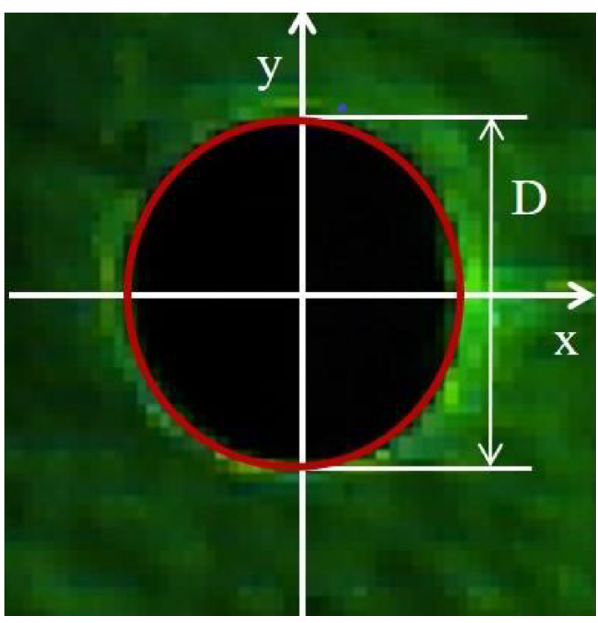

(a) mode I caustic spots

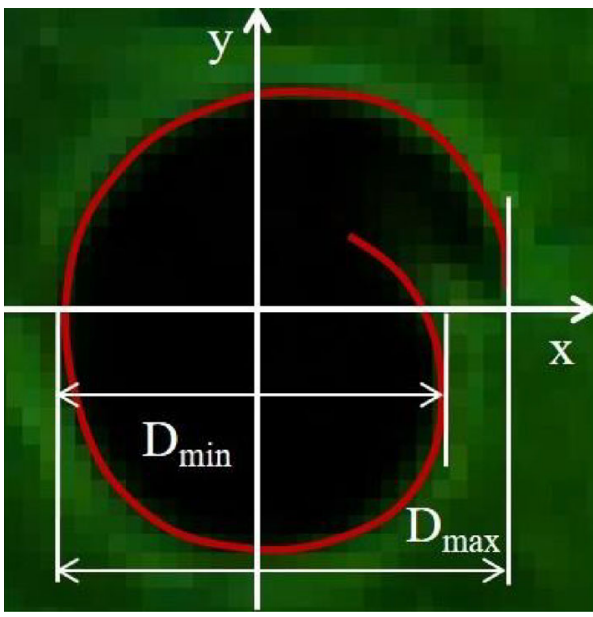

(b) mixed mode I-II caustic spots

Fig. 2 Two types of caustic images

where, $\varepsilon$ is a constant (usually 1 or 2), $d$ is the thickness of the specimen, $\xi_{\mathrm{r}, \mathrm{t}}$ is the light anisotropy coefficient of the material, and $c_{\mathrm{r}, \mathrm{t}}$ is the stress optical constant.

If the growth of the crack length after time $\Delta t$ is $\Delta z$, then $\Delta z$ at time $t_{\mathrm{i}}$ can be expressed as

$\Delta z\left(t_{\mathrm{i}}\right)=\sqrt{\Delta x^{2}\left(t_{\mathrm{i}}\right)+\Delta y^{2}\left(t_{\mathrm{i}}\right)}$,

where, $\Delta x\left(t_{\mathrm{i}}\right)$ and $\Delta y\left(t_{\mathrm{i}}\right)$ are the displacements in the $x$ and $y$ directions, respectively, at time $t_{\mathrm{i}}$ during the crack propagation process. The crack growth rate $v$ can be obtained by the differential of the crack length and time interval.

According to caustics theory, the equations of the caustic curve of the specimen in the reference plane can be expressed as (Yang et al. 2018) $x^{\prime}=r_{0}\left[\cos \left(\theta+2 \operatorname{acrtan} \frac{K_{\mathrm{II}}}{K_{\mathrm{I}}}\right)+\frac{2}{3} \cos \frac{3}{2}\left(\theta+2 \operatorname{acrtan} \frac{K_{\mathrm{II}}}{K_{\mathrm{I}}}\right)\right] \lambda_{\mathrm{m}}$,

$y^{\prime}=r_{0}\left[\sin \left(\theta+2 \operatorname{acrtan} \frac{K_{\mathrm{II}}}{K_{\mathrm{I}}}\right)+\frac{2}{3} \sin \frac{3}{2}\left(\theta+2 \operatorname{acrtan} \frac{K_{\mathrm{II}}}{K_{\mathrm{I}}}\right)\right] \lambda_{\mathrm{m}}$,

where, $\lambda_{\mathrm{m}}$ is the magnification of light, and $r_{0}$ is the radius of the initial curve, which can be expressed as

$r_{0}=\left(\frac{3 \varepsilon Z_{0} d c_{\mathrm{r}, \mathrm{t}}}{2 \lambda_{\mathrm{m}} \sqrt{2 \pi}}\right)^{\frac{2}{5}}\left(K_{\mathrm{I}}^{2}+K_{\mathrm{II}}^{2}\right)^{\frac{1}{5}}$

Therefore, the mode-I dynamic crack stress intensity factor $K_{\mathrm{I}}^{\mathrm{d}}$ and the mode-II dynamic crack stress intensity factor $K_{\mathrm{II}}^{\mathrm{d}}$ can be expressed as (Rosakis 1980)

$K_{\mathrm{I}}^{\mathrm{d}}=\frac{2 \sqrt{2 \pi} F(v)}{3 g^{5 / 2} z_{0} c d} D_{\max }^{5 / 2}$,

$K_{\mathrm{II}}^{\mathrm{d}}=\mu K_{\mathrm{I}}^{\mathrm{d}}$,

where, $z_{0}(=0.9 \mathrm{~m})$ is the distance between the reference plane and the specimen, $g$ is the stress intensity factor coefficient, which is 3.17 ( $\mathrm{Sih} 1981$ ), $D_{\max }$ is the maximum diameter of the caustic spot, $\mu$ is the scale factor, and $F(v)$ is the speed adjustment factor, which can be expressed as

$F(v)=\frac{4 \beta_{1} \beta_{2}-\left(1+\beta_{2}^{2}\right)^{2}}{\left(1+\beta_{2}^{2}\right)\left(\beta_{1}^{2}-\beta_{2}^{2}\right)}$,

where, $\beta_{i}^{2}=1-\left(v / c_{i}\right)^{2}(i=1,2)$, and $c_{1}$ and $c_{2}$ are the compressive and shear wave velocities, respectively.

\subsection{Testing system}

The test combined a new DLDC system with a stress-wave loading system (Fig. 3). The DLDC system comprised a high-speed digital camera (FASTCAM SA5 (16G); Photron, Japan), two convex lenses (focal length $1500 \mathrm{~mm}$ and diameter $300 \mathrm{~mm}$ ), an expander (LCht 3X $532 \mathrm{~nm}$;

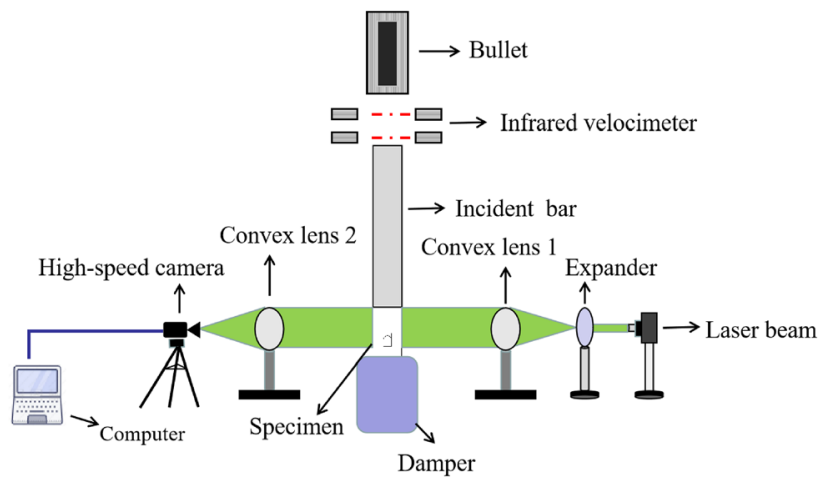

Fig. 3 Testing system 
Edmund Optics, USA), and a green laser (LWGL300 $1500 \mathrm{~mW}$ : $50 \mathrm{~mW}$, ChangChun Laser Company, China). When the system is working, the beam emitted from the laser is diffused after passing through the beam expander, whereupon it passes through convex lens 1, the PMMA specimen, and convex lens 2, and finally the presented image enters the high-speed camera.

The SHPB experimental system comprised a pneumatic power device, a bullet, an infrared velocimeter, an incident bar, and a damper. Unlike the traditional SHPB, the stresswave loading system used here had no transmitter bar, the reason being that the wave impedance matching between the steel rod and the Plexiglas was poor, and the stress wave was transmitted less. Meanwhile, an SHPB was used as the loading system in this experiment so that a bullet and an incident bar could be used to generate a dynamic stress wave that then acted on the specimen, thereby avoiding the need for a transmitter bar. The bullet and incident bar used in the experiment were cylindrical steel rods with lengths of 400 and $2000 \mathrm{~mm}$, respectively; the elastic modulus $E_{\mathrm{b}}$ of the bar was $206 \mathrm{GPa}$, and the measured longitudinal wave velocity was $5123 \mathrm{~m} / \mathrm{s}$.

Because of the difference in movement between the contact surface of the bar and the specimen in the transverse direction, the test process involved a friction force that would have prevented the transverse deformation at the contact surface of the specimen and destroyed the onedimensional stress state of the test piece, thereby causing abnormal damage to the test piece, as shown in Fig. 4, where the blue dashed rectangle indicates the trajectory offset and the red dashed circles indicate the stress concentration points. Therefore, during the impact experiment, it was necessary to lubricate the bars in contact with both ends of the test piece, such as by applying Vaseline.

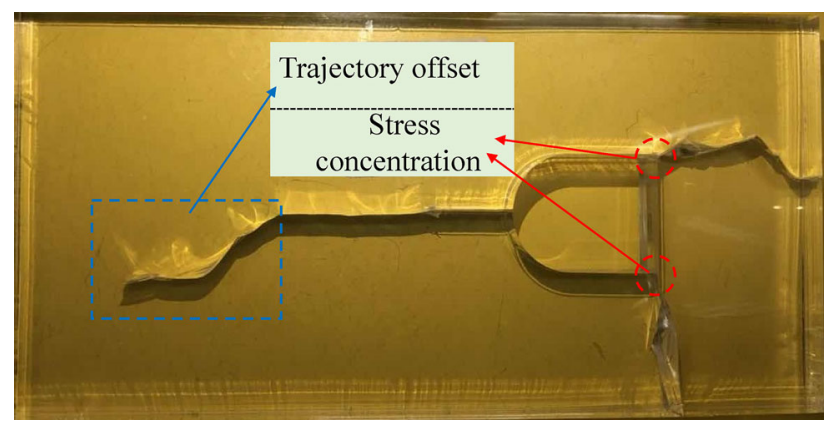

Fig. 4 Abnormal failure caused by friction

\section{Experimental program}

\subsection{Specimen design}

Figure 5 shows the geometric dimensions of the semicircular-arch roadway specimen. Given the actual engineering background, it is assumed that the width of the roadway is $8 \mathrm{~m}$, the height is $10 \mathrm{~m}$, and the radius of the semicircular arch is $4 \mathrm{~m}$. Based to these conditions, similar simulation experiments were carried out, and the roadway size was reduced using a similarity ratio of 400:1; the width of the test roadway was $20 \mathrm{~mm}$, the height was $25 \mathrm{~mm}$, and the radius of the semicircular arch was $10 \mathrm{~mm}$. Also, the length of the entire test piece was $140 \mathrm{~mm}$, the width was $70 \mathrm{~mm}$, and the thickness was $10 \mathrm{~mm}$. Pre-fabricated cracks with a length of $15 \mathrm{~mm}$ and a width of $0.5 \mathrm{~mm}$ were set at different positions on the top of the semicircular arch. The material of the tested piece was PMMA, the relevant parameters of which are given in Table 1 (Karimzada and Maigre 2000).

To allow the crack to propagate smoothly, an initial crack was machined at different positions on the top of the semicircular arch. The size of the incident bar meant that the specimen could not be made arbitrarily large. Also, it was necessary to ensure that the semicircular-arch tunnel in the middle of the specimen had a certain size. To reduce the influence of the boundaries of the test piece on the crack propagation, when designing its size, the width of the test piece was slightly larger than the diameter of the incident bar $(50 \mathrm{~mm})$, thereby ensuring that when the stress wave was transmitted to the specimen, it affected all the cracks within the purple dotted line shown in Fig. 6. In this way, the interference of the upper and lower boundaries on the crack propagation was reduced. The principle for selecting the length of the specimen was to make it as long as possible. However, because of the influences of the elastic modulus, shear modulus, and thickness of the test piece, the best length obtained through repeated experiments to prevent the test piece from breaking longitudinally from its middle during the impact process was $140 \mathrm{~mm}$. In many of the tests, the cracks usually propagated in the purple area in Fig. 6, and in very few tests did the cracks propagate to the red area. If a crack propagated to the red region, then its propagation was affected by the left boundary and it deflected suddenly, as shown in Fig. 7. Therefore, the scope for studying crack propagation herein is within the purple dashed line.

\subsection{Test operation}

When setting up a DLDC system, it is important to place all the equipment on a suitable horizontal surface to ensure 


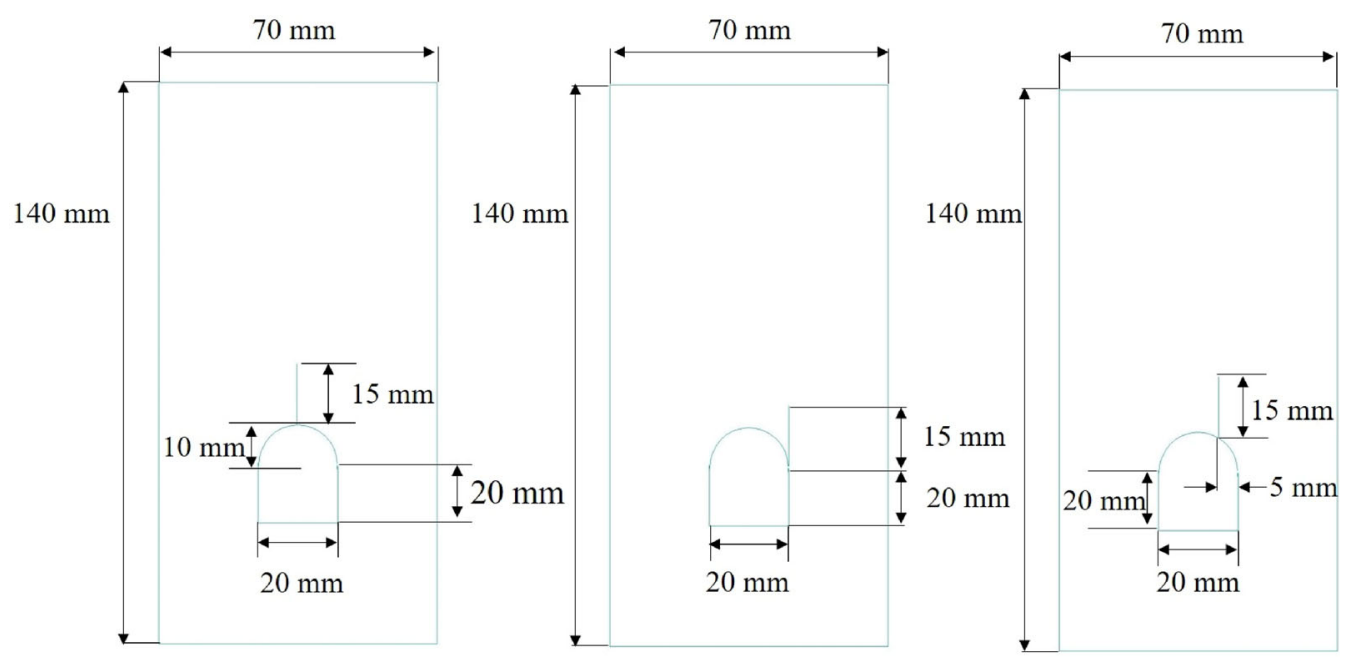

Fig. 5 Specimen geometry

Table 1 Mechanical properties of PMMA

\begin{tabular}{lll}
\hline Mechanical property & Symbol & Value \\
\hline Density $\left(\mathrm{kg} / \mathrm{m}^{3}\right)$ & $\rho$ & 1180 \\
Dynamic Young's modulus $(\mathrm{GPa})$ & $E_{\mathrm{d}}$ & 6.1 \\
Poisson's ratio & $V_{\mathrm{d}}$ & 0.31 \\
Velocity of compressive waves $(\mathrm{m} / \mathrm{s})$ & $C_{\mathrm{p}}$ & 2320 \\
Velocity of shear waves $(\mathrm{m} / \mathrm{s})$ & $C_{\mathrm{s}}$ & 1260 \\
Stress optical constant $\left(\mathrm{m}^{2} / \mathrm{N}\right)$ & $C$ & $0.88 \times 10^{-10}$ \\
Shear modulus $(\mathrm{GPa})$ & $G$ & 1.28 \\
\hline
\end{tabular}

that the laser is perpendicular to the surface of the specimen. The high-speed camera operated at $65-100 \mathrm{fps}$ and generated frames containing $448 \times 224$ pixels. During a test, experimenter $\mathrm{Li}$ was responsible for adjusting the

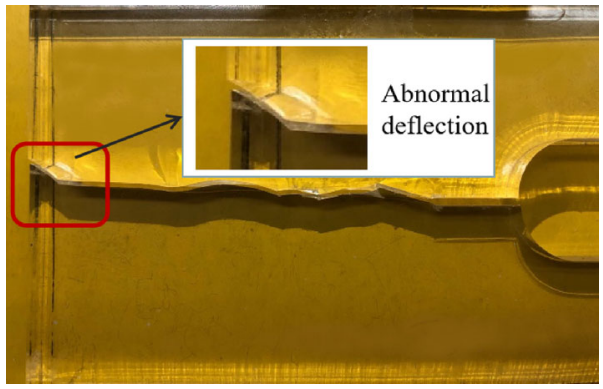

Fig. 7 Crack propagation affected by boundary

incident pressure of the bullet; to keep the loading rate as constant as possible, the air pressure was adjusted to be $0.20 \pm 0.01 \mathrm{MPa}$. When experimenter Zhang heard the impact sound, he immediately pressed the video button; in this experiment, the high-speed camera had a post-trigger

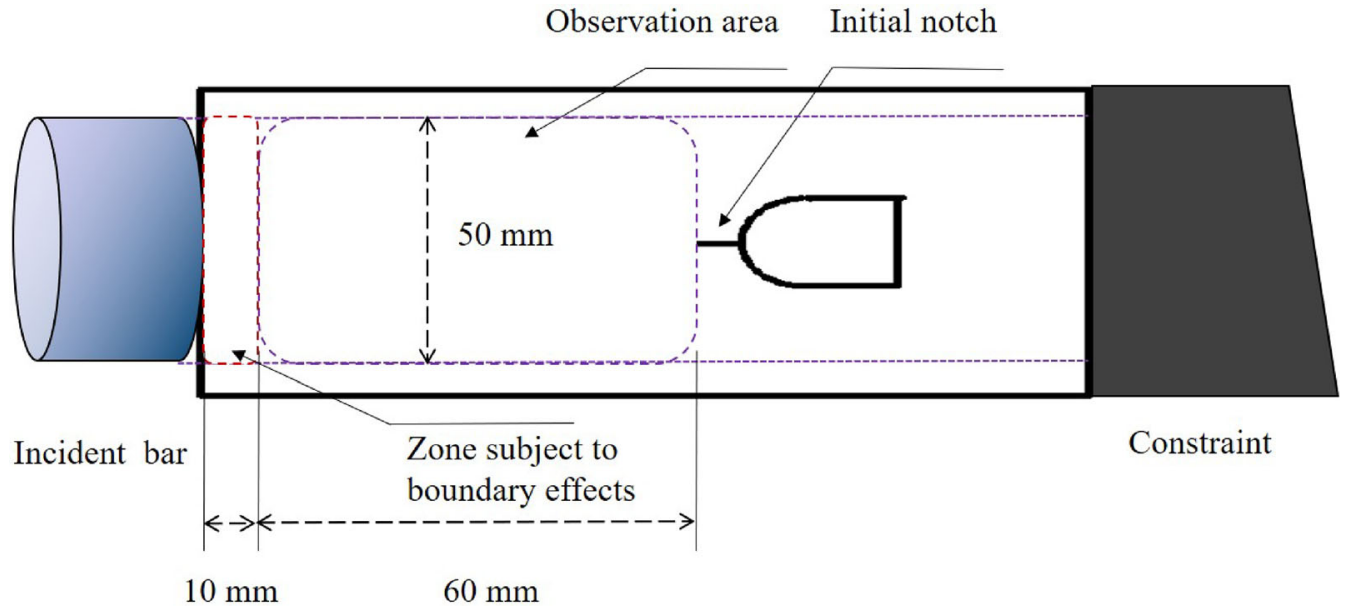

Fig. 6 Study area of specimen 
Table 2 Bullet velocity and pressure for each specimen

\begin{tabular}{llll}
\hline Specimen & Specimen A & Specimen B & Specimen C \\
\hline Bullet velocity $(\mathrm{m} / \mathrm{s})$ & 4.53 & 4.51 & 4.52 \\
Air pressure $(\mathrm{MPa})$ & 0.2 & 0.2 & 0.21 \\
\hline
\end{tabular}

mode and recorded frames for $2 \mathrm{~s}$ before the button was pressed, thereby ensuring that the test process was recorded completely. After the test, based on the velocity measured by the infrared velocimeter, the test records of three groups of specimens (with different crack positions) were selected randomly as the test results. The results are given in Table 2 and show that the emission pressures and velocities for specimens $\mathrm{A}-\mathrm{C}$ were almost the same.

\section{Results and discussion}

\subsection{Crack propagation paths of specimens}

Figure 8 shows the crack propagation paths of three groups of semicircular-arch roadway specimens with different crack positions. The pre-fabricated crack of specimen A was located on the central axis of the specimen; having been impacted, it expanded approximately in a straight line along the central axis, fluctuating up and down in a small range. The pre-fabricated crack of specimen $B$ was $5 \mathrm{~mm}$ from the central axis and bent downward to form an approximately circular arc after being impacted; when the crack extended near the central axis, it exhibited very little vertical expansion. The pre-fabricated crack of specimen $\mathrm{C}$ was located at the edge of the semicircular-arch roadway, and the crack propagation was similar to that of specimen B. However, the degree of circular extension of the crack of specimen $\mathrm{C}$ was more obvious than that of specimen B. Similarly, the crack of specimen C could not continue to expand downward after extending to the central axis, but instead it moved horizontally along the central axis.

\subsection{Dynamic caustics diagrams at typical moments}

Because of space limitations, Fig. 9 shows the partial caustics diagrams of specimens AC at different moments with pre-fabricated cracks at different positions. Note that the time regulation in this study was the moment before the caustic spots changes is zero. As can be seen, even if the pre-fabricated cracks were at different positions, the areas of the caustics spots of their tips changed from small to large in the initial stage of impact for each specimen. This shows that the increase of the caustic spots at this stage was due only to the impact load acting on the crack tip to cause energy concentration. When the energy accumulated at the crack tip reached a certain level, the crack began to expand, i.e., the caustic spot moved.

The caustic-spot images for specimen A show that the shape of the caustic spot at the crack tip at any moment is similar to that of the type-I caustic spots in Fig. 2a. Combined with the crack propagation trajectory of specimen A (shown in Fig. 8), it can be judged that when the pre-fabricated crack is on the central axis of the semicircular-arch roadway, the crack propagation after the specimen is impacted conforms to mode-I crack propagation. Also, Fig. 9 shows that during the crack propagation, the caustic spot is not always large; instead, it suddenly becomes smaller and then becomes larger.

The caustic-spot pattern of specimen B in Fig. 9 shows that the shape of the caustic spots sometimes conforms to the I-II mixed type of caustic pattern in Fig. 2b during crack propagation, e.g., at $t=93.33 \mu$ s. Sometimes, the shape conforms to the type-I caustics in Fig. 2a, e.g., at $t=466.66 \mu \mathrm{s}$. The results show that the crack propagation process is a mixture of modes I and I-II when the prefabricated crack is $5 \mathrm{~mm}$ from the central axis. After the crack stops growing, the shape of the caustic becomes smaller and smaller, and its shape changes from mixed mode I-II to type I.

The caustic spots for specimen $\mathrm{C}$ show that before the crack begins to move, the size of the caustic spot at the tip of the preformed crack is changing constantly, reflecting the fact that the energy at its tip is also changing constantly. In the initial stage of energy accumulation, the caustics resemble a circle, indicating that they are type-I caustics. When the crack begins to move, the caustic spots conform to the mixed I-II caustic pattern in Fig. 2b, and the size is also changing constantly. When the crack stops growing, the caustics becomes mode I.

\subsection{Dynamic stress intensity factor at crack tip}

Because of the limited exposure time of the high-speed camera, the outer edges of the captured images of the moving caustic spots were blurred, and this ambiguity was the main source of error in the test results. Therefore, we used the deblurring and binarization technologies in MATLAB to focus on the contours of the caustic spots. Equations (8) and (9) show that regardless of whether we are dealing with $K_{\mathrm{I}}^{\mathrm{d}}$ or $K_{\mathrm{II}}^{\mathrm{d}}$, its size has a linear trend with the five-halves power of the caustic-spot diameter. If the caustic-spot contour processing is insufficiently accurate, then the error in the calculated DSIF value will be magnified many times. Therefore, having processed the causticspot contour perfectly, the MATLAB program was used to obtain the caustic-spot diameter accurately as possible. 


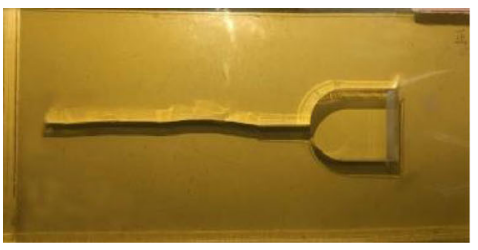

(a) Specimen A

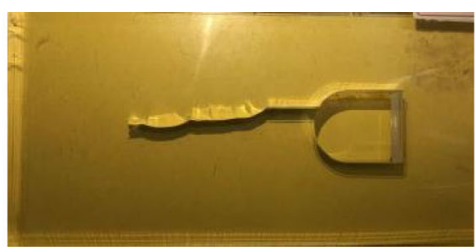

(b) Specimen B

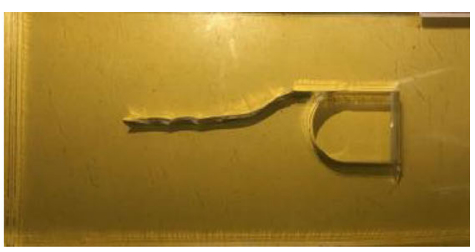

(c) Specimen C

Fig. 8 Crack growth traces

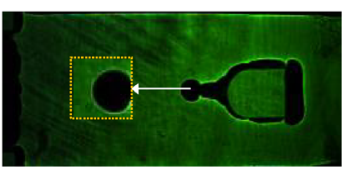

$46.08 \mu \mathrm{s}$

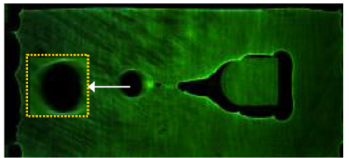

$1520.73 \mu \mathrm{s}$

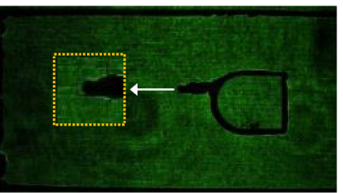

$13.33 \mu \mathrm{s}$

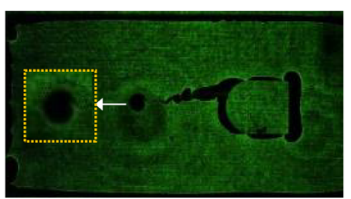

$973.33 \mu \mathrm{s}$

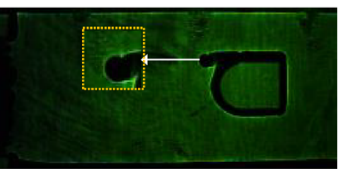

$15.36 \mu \mathrm{s}$

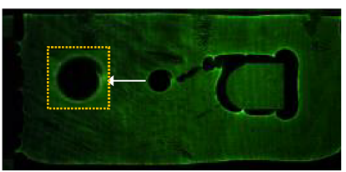

$1182.79 \mu \mathrm{s}$

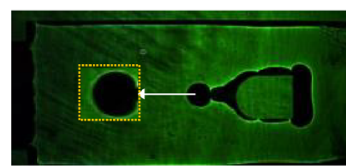

$276.49 \mu \mathrm{s}$

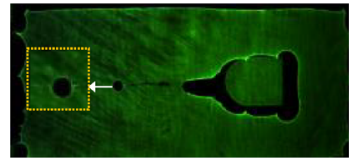

$2457.75 \mu \mathrm{s}$

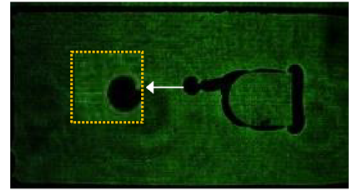

$93.33 \mu \mathrm{s}$

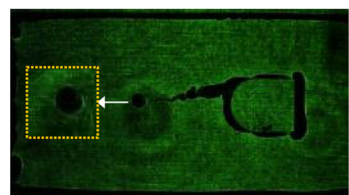

$1213.33 \mu \mathrm{s}$

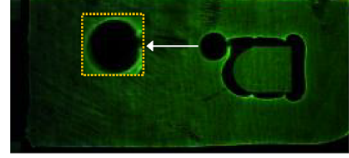

$138.24 \mu \mathrm{s}$

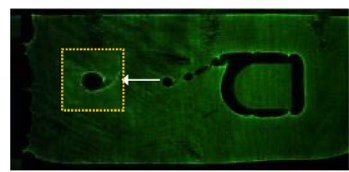

$1290.32 \mu \mathrm{s}$

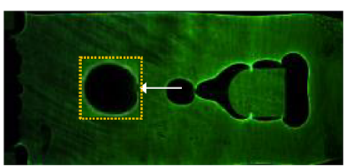

$829.49 \mu \mathrm{s}$

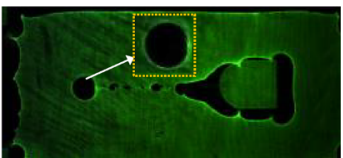

$2749.6 \mu \mathrm{s}$

(a) Specimen $\mathrm{A}$

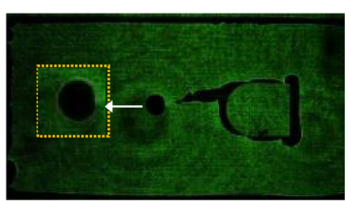

$466.66 \mu \mathrm{s}$

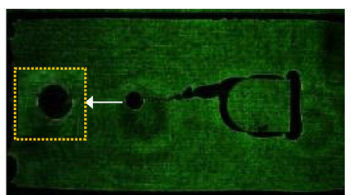

$1466.66 \mu \mathrm{s}$

(b) Specimen B

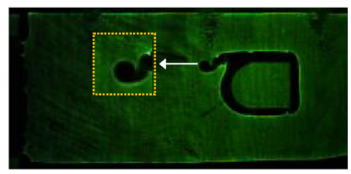

$691.24 \mu \mathrm{s}$

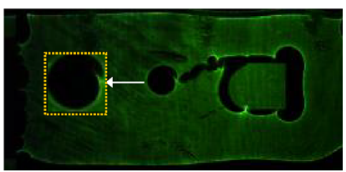

$1643.62 \mu \mathrm{s}$

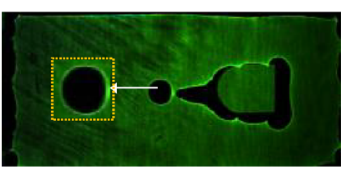

$1182.79 \mu \mathrm{s}$

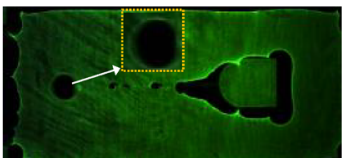

$2903.22 \mu \mathrm{s}$

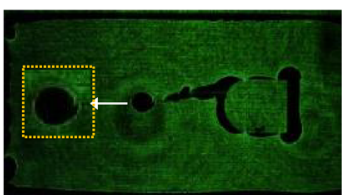

$920 \mu \mathrm{s}$

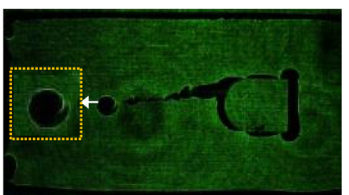

$1840 \mu \mathrm{s}$

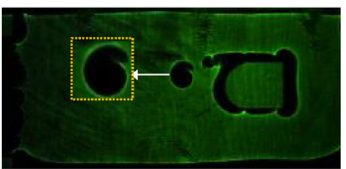

$921.65 \mu \mathrm{s}$

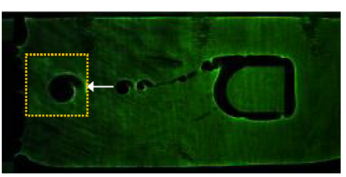

$2319.5 \mu \mathrm{s}$

(c) Specimen C

Fig. 9 Dynamic caustic image patterns at crack in specimens for different locations of pre-fabricated crack

Because the specimen fractured because of multiple actions after the internal stress wave was reflected, the entire fracture process took a long time. Through data processing, it was found that the law governing how the 
DSIF changed was roughly the same throughout the whole process, with the change curve being almost the same in multiple time periods. Therefore, we selected the change of the DSIF during the first half of the fracture process for analysis. Using the caustic method, the curve of the DSIF at the crack tip of each specimen was calculated with time (see Fig. 10). Here, the time from when the crack-tip caustic speckles begin to appear to when the caustic spot moves is defined as the initial energy accumulation stage (IEAS), and the IEAS times of specimens A-C are 261.13, 120 , and $122.88 \mu \mathrm{s}$, respectively. When the pre-fabricated crack is on the central axis, the energy accumulation takes longer, and when the pre-fabricated crack shifts to the edge of the semicircular arch, the IEAS time shortens.

The pre-fabricated crack of specimen A is on the central axis, and when the specimen is impacted, the crack-tip energy starts to converge. In Fig. 9a, the corresponding images show that the size of the caustic spot changes. When $K_{\mathrm{I}}^{\mathrm{d}}=1.81 \mathrm{MPa} \mathrm{m}^{1 / 2}$, the crack begins to move. The results show that the mode-I fracture toughness of the specimen is $1.81 \mathrm{MPa} \mathrm{m}^{1 / 2}$ when the pre-fabricated crack is on the central axis. After the energy accumulation stage, the DSIF changes constantly, reaching the maximum value of $2.40 \mathrm{MPa} \mathrm{m}{ }^{1 / 2}$. From crack impact until the caustic spot no longer changes, the whole process involves only $K_{\mathrm{I}}^{\mathrm{d}}$, which is pure type-I crack propagation.

Figure $10 \mathrm{~b}$ shows that the crack starts to move when $K_{\mathrm{I}}^{\mathrm{d}}=0.83 \mathrm{MPa} \mathrm{m}^{1 / 2}$ and $K_{\mathrm{II}}^{\mathrm{d}}=0.5 \mathrm{MPa} \mathrm{m}^{1 / 2}$. This shows that when the pre-fabricated crack is $5 \mathrm{~mm}$ from the central axis, the fracture toughness of type $\mathrm{I}$ is $0.83 \mathrm{MPa} \mathrm{m}^{1 / 2}$, and that of type II is $0.50 \mathrm{MPa} \mathrm{m}{ }^{1 / 2}$. The process of crack growth is not simply type-I crack growth or mixed I-II growth; instead, type I and mixed type I-II appear alternately. For $t=150-266.66 \mu \mathrm{s}$, the DSIF involves only $K_{\mathrm{I}}^{\mathrm{d}}$; for $t=266.66-320 \mu \mathrm{s}, \quad K_{\mathrm{I}}^{\mathrm{d}}$ and $K_{\mathrm{II}}^{\mathrm{d}}$ coexist; for $t=320-866.66 \mu \mathrm{s}$, the DSIF again involves only $K_{\mathrm{I}}^{\mathrm{d}}$; for $t=866.66-1413.33 \mu \mathrm{s}$, the DSIF is of mixed I-II type.

For specimen C, only $K_{\mathrm{I}}^{\mathrm{d}}$ was involved for $t=0-61.44 \mu \mathrm{s}$, and the pattern of caustic speckle was pure type I. After $61.44 \mu \mathrm{s}$, mixed I-II type caustic speckle appeared. At $t=122.88 \mu \mathrm{s}$, the crack tip completed the energy accumulation stage and then began to propagate. The fracture toughness of type I was $1.70 \mathrm{MPa} \mathrm{m}^{1 / 2}$, and the fracture toughness of type II was $1.53 \mathrm{MPa} \mathrm{m}{ }^{1 / 2}$. The maximum value of $K_{\mathrm{I}}^{\mathrm{d}}$ was $3.59 \mathrm{MPa} \mathrm{m}{ }^{1 / 2}$ and that of $K_{\mathrm{II}}^{\mathrm{d}}$ was $7.80 \mathrm{MPa} \mathrm{m}{ }^{1 / 2}$, those maximum values were not reached at the same time.

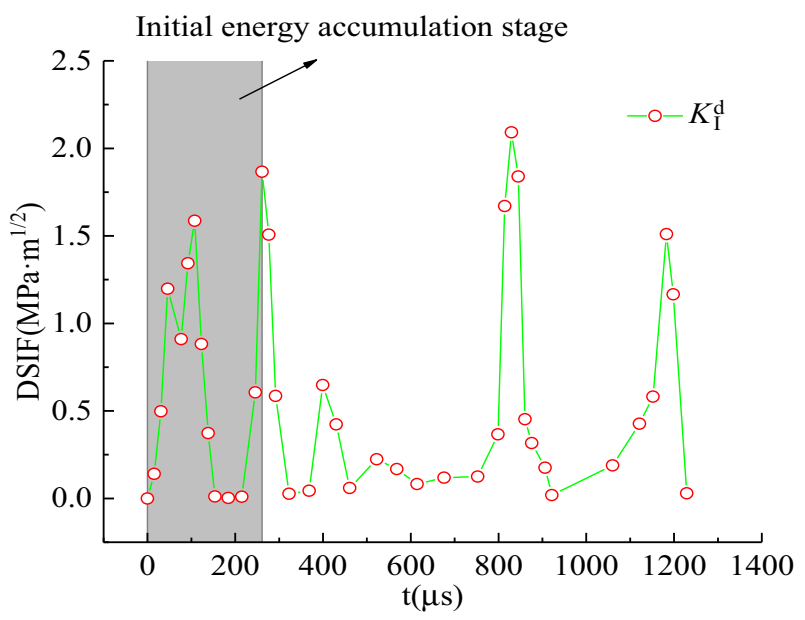

(a) Specimen A

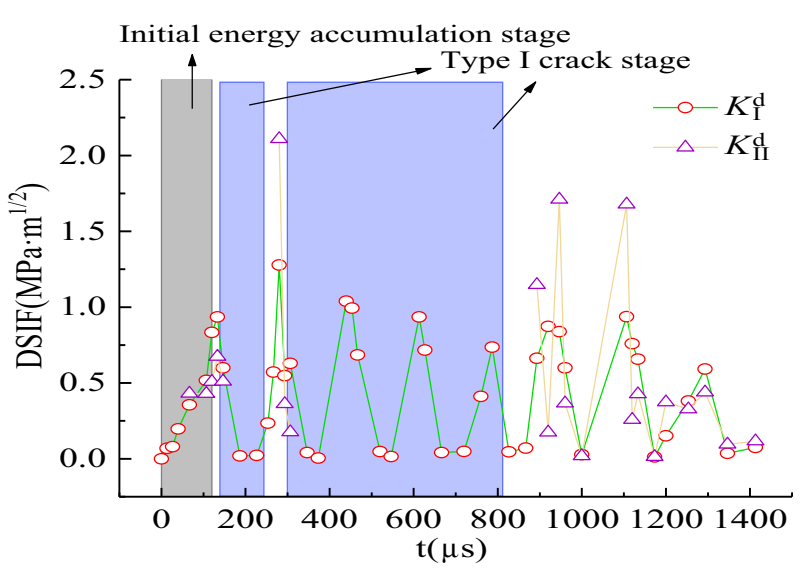

(b) Specimen B

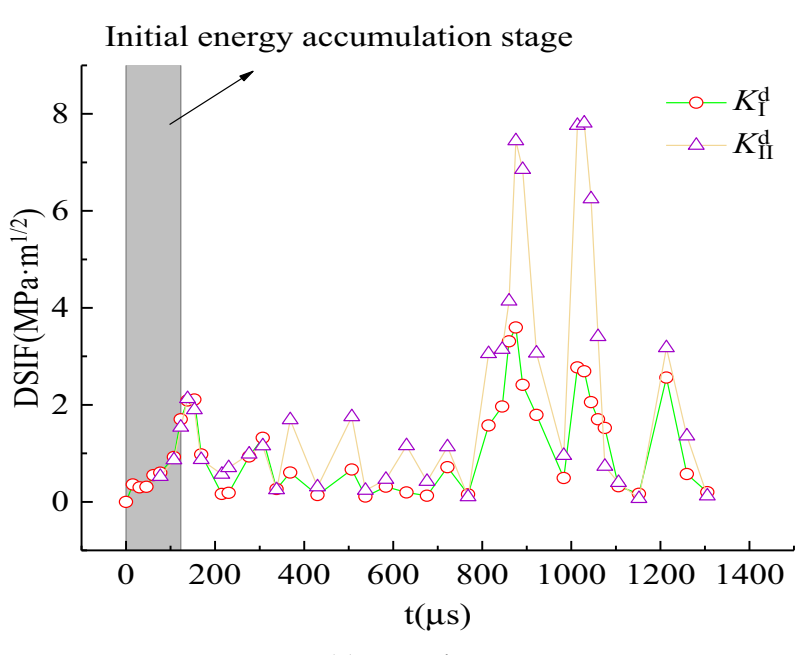

(c) Specimen C

Fig. 10 Curve of dynamic stress intensity factor (DSIF) versus time for each specimen 


\subsection{Influence of location of pre-fabricated crack on crack propagation}

For an intuitive view of the crack in motion, the images of the moving caustic spot were processed. Taking the tip of the pre-fabricated crack as the origin $\mathrm{O}$, the horizontal left direction is the positive direction of $X$, and the vertical downward direction is the positive direction of $Y$. Curves of the displacement of the crack tip in the $X$ and $Y$ directions with time were drawn, and the crack change in the first half of the fracture process was analyzed (Fig. 11).

In Fig. 11, the displacement-time diagram of the crack tip of each specimen presents stepped curves in the $X$ and $Y$ directions. This shows that under the action of impact loading, the crack propagation is not completed at once; instead, it pauses after extending a certain distance, and then expands again when the energy accumulates to a certain value. The continuous change of the DSIF in Fig. 10 verifies this phenomenon from the side. Because of the energy consumed by crack growth, the DSIF of the crack tip decreases during movement. When the value drops below the crack fracture toughness, the crack stops expanding. After waiting for the energy to accumulate and exceed the fracture toughness again, the crack continues to grow. In Fig. 11a, when the crack expands along the central axis, it floats upward in a small range, thereby giving it negative displacement in the $Y$ direction. However, the change of the caustic spot in Fig. 9a suggests that the crack propagation of specimen A conforms to the pure type-I law. Figure $11 \mathrm{~b}$ shows that the crack displacements in the $X$ and $Y$ directions are almost synchronous. At the end of the crack propagation trajectory, specimen $\mathrm{B}$ still has a small range for displacement in the $Y$ direction, which is consistent with the fracture trajectory of the actual specimen in Fig. 8b. As can be seen, the displacement time in the $Y$ direction is relatively concentrated (see Fig. 11c) and is almost completed in $t=860.21-1075.26 \mu \mathrm{s}$. In the other time periods, there is only a small range for displacement in the $Y$ direction.

When the preformed crack is on the central axis, the crack growth is pure mode I. The energy of the impact loading mainly makes the crack move in the $X$ direction, and when the pre-fabricated crack moves upward, the mixed I-II mode appears. With increasing displacement of the pre-fabricated crack, its displacement in the $Y$ direction increases.

According to Eq. (4), the displacements of the crack in the $X$ and $Y$ directions are combined as a vector to obtain the actual displacement $\Delta z$. The derivative of the displacement $\Delta z$ is then calculated with respect to time, and the crack growth rate $V_{\mathrm{z}}$ with time is obtained (see Fig. 12). As can be seen, the pre-fabricated crack that is $5 \mathrm{~mm}$ from the central axis reaches its maximum speed first, followed

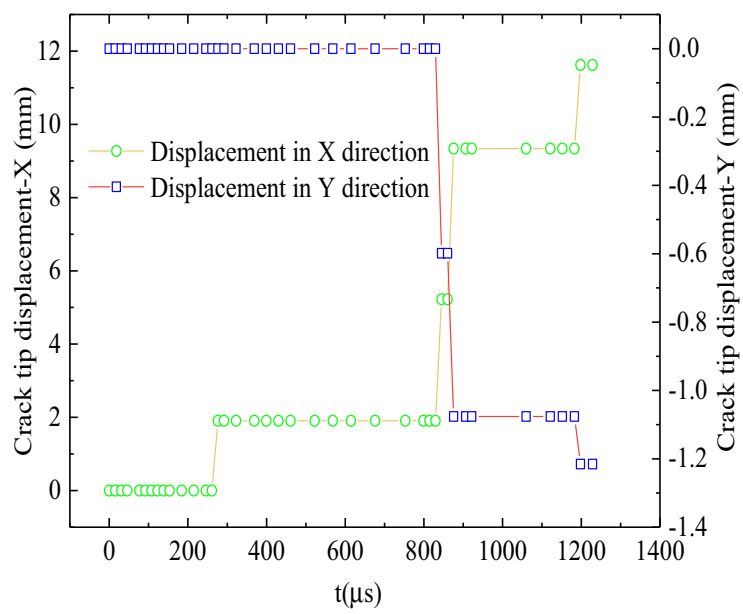

(a) Specimen A

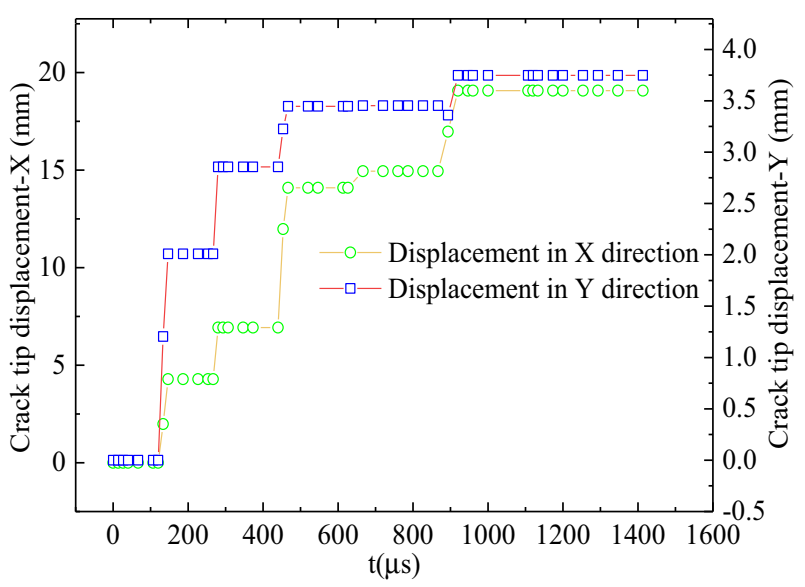

(b) Specimen B

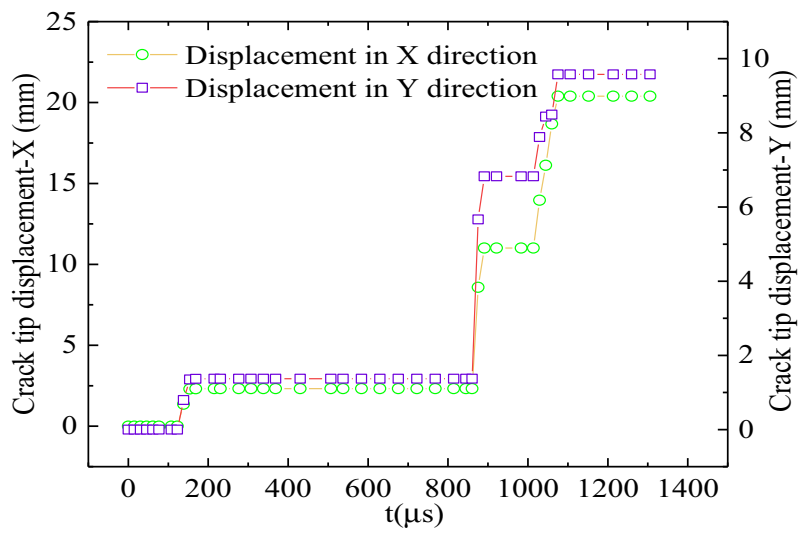

(c) Specimen C

Fig. 11 Time histories of propagation of crack tip

by the one at the edge of the semicircular-arch roadway, and then the one on the central axis. As the pre-fabricated crack shifts upward from the central axis, the maximum 


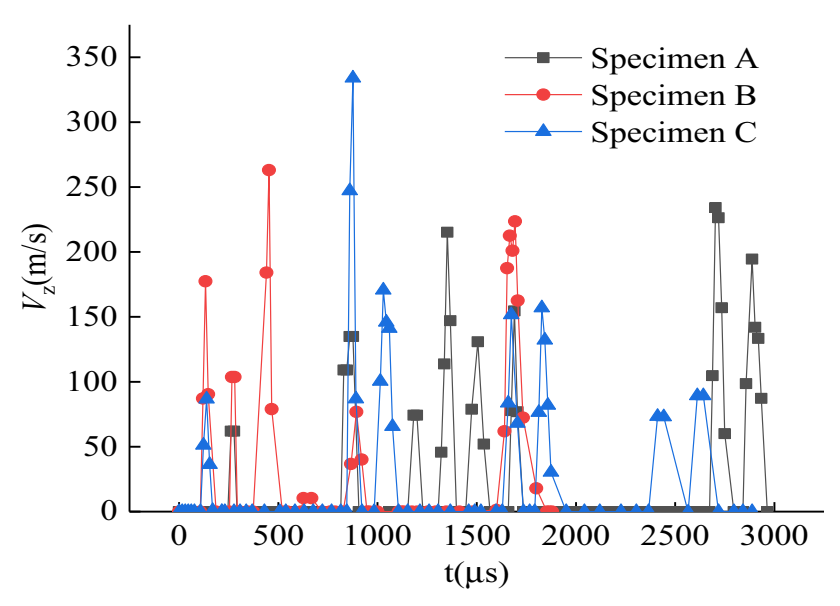

Fig. $12 V_{\mathrm{z}}$ velocity of crack growth versus time

speed reached during the crack propagation process gradually increases. The first time that the stress acts on the crack tip is mainly to make the crack-tip energy converge. When the fracture toughness of the specimen reaches, the crack movement has speed. With the disappearance of the tip stress, the crack velocity decreases gradually, and when the reflection stress acts on the crack tip again, the crack speed increases again.

Figure 13 shows how $K_{\text {II }}^{\text {d }}$ for specimens B and C changes with displacement in the $X$ direction. The blue dotted lines in Fig. 13 show that when the displacements of specimens $\mathrm{B}$ and $\mathrm{C}$ in the $X$ direction reach the same (or approximately the same) value, the value of $K_{\mathrm{II}}^{\mathrm{d}}$ for specimen $\mathrm{C}$ is greater than that of specimen $\mathrm{B}$. This shows that when the pre-fabricated crack is located at the edge of the roadway, the stress concentration received by the crack tip is higher. For a given displacement, the shear stress of the crack of specimen $\mathrm{C}$ is greater during the propagation process. When the crack propagates along the central axis,

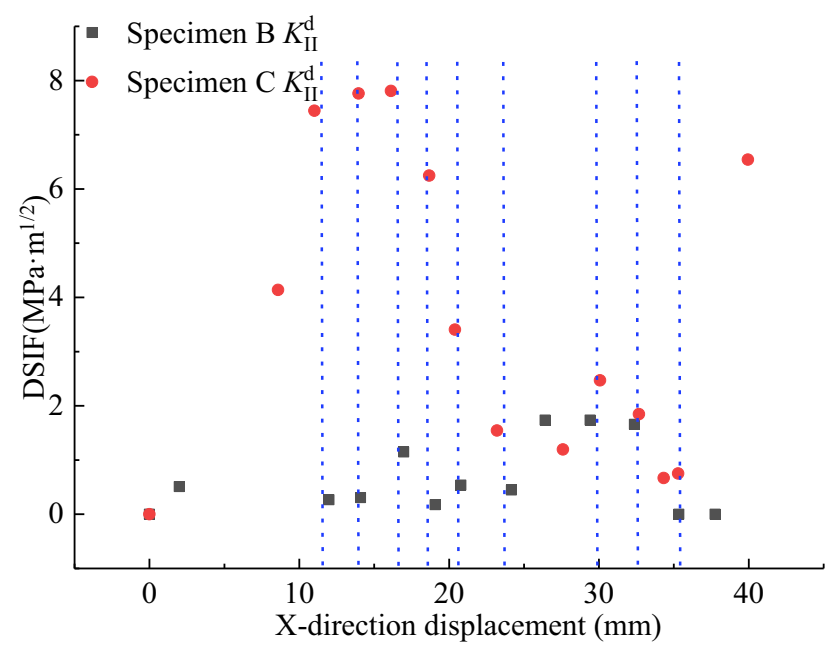

Fig. 13 Crack propagation DSIF versus displacement in $X$ direction it still has a high value of $K_{\mathrm{II}}^{\mathrm{d}}$, which is due to the reflection of the stress wave on the semicircular-arch surface, which causes a stress imbalance between the upper and lower sides of the crack.

\subsection{Analysis of crack growth process}

When the specimen was subjected to the stress wave from the incident rod, part of the stress wave was transmitted into the specimen and acted on the crack tip therein, but some of the stress wave was reflected back to the incident rod when it touched the left side of the specimen. Previous research shows that the smaller the contact surface between the test specimen and the bar, the greater the specific gravity of the reflected wave ( $\mathrm{Li}$ et al. 2017). Because there was no transmission rod, the effect of transmitted waves was not considered. After calculation, the time for the stress wave to travel back and forth inside the incident rod was approx. $780 \mu$ s. Figure 11 shows that after the test piece was subjected to the stress wave, a larger displacement occurred at $800 \mu \mathrm{s}$, especially in specimens A and C. This time coincided with when the stress wave was reflected back and forth by the incident bar once and then acted on the specimen again. Second, because of the curved surface of the semicircular-arch roadway, the transmission and reflection of the stress wave inside the specimen was not completely in the horizontal direction, thereby preventing part of the stress wave from acting on the crack tip. These factors led to the suspension of crack growth and the drastic changes in the DSIF.

Figure 14 is a simplified schematic of how the reflected stress wave affects the crack. When energy accumulates at the crack tip for the first time, the semicircular-arch roadway attenuates the stress wave to form $P_{\mathrm{d}}$ when it is transmitted to the nearby area. However, the stress wave $P_{\mathrm{i}}$ on both sides of the semicircular-arch roadway does not pass through the roadway, so $P_{\mathrm{i}}$ is greater than $P_{\mathrm{d}}$. Therefore, the displacement of the crack tip after energy accumulation is completed deflects downward rather than upward, and the crack motion is still under the action of the stress wave. Because the crack motion trajectory is an arc, the stress wave is decomposed in the radial and tangential directions of the arc to obtain $P_{\mathrm{r}}$ and $P_{\mathrm{t}}$. Here, $\alpha$ is the angle between the principal stress and its component in the radial direction of the crack trajectory, and the decomposition can be expressed as

$$
\left\{\begin{array}{l}
P_{1 \mathrm{r}}=P_{1} \cdot \cos \alpha, P_{1 \mathrm{t}}=P_{1} \cdot \sin \alpha \\
P_{2 \mathrm{r}}=P_{2} \cdot \cos \alpha, P_{2 \mathrm{t}}=P_{2} \cdot \sin \alpha \\
\cdot \\
\cdot \\
P_{\mathrm{mr}}=P_{\mathrm{m}} \cdot \cos \alpha, P_{\mathrm{mt}}=P_{\mathrm{m}} \cdot \sin \alpha
\end{array}\right.
$$




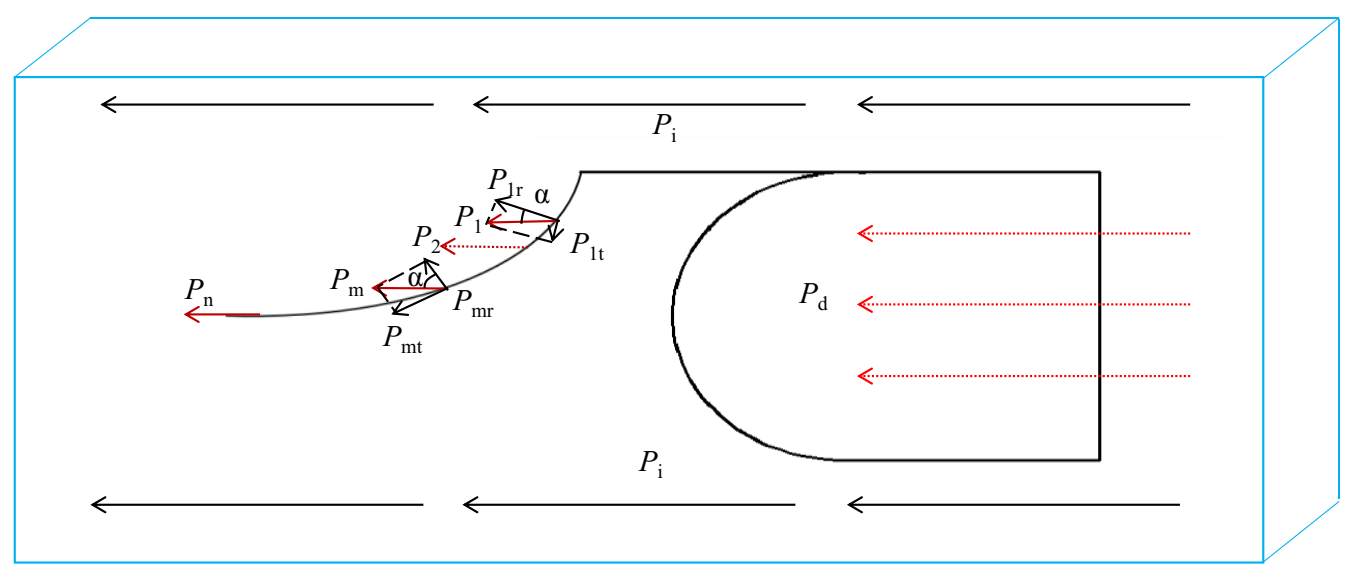

Fig. 14 Effect of stress wave on crack

Fig. 15 Meshed output bar

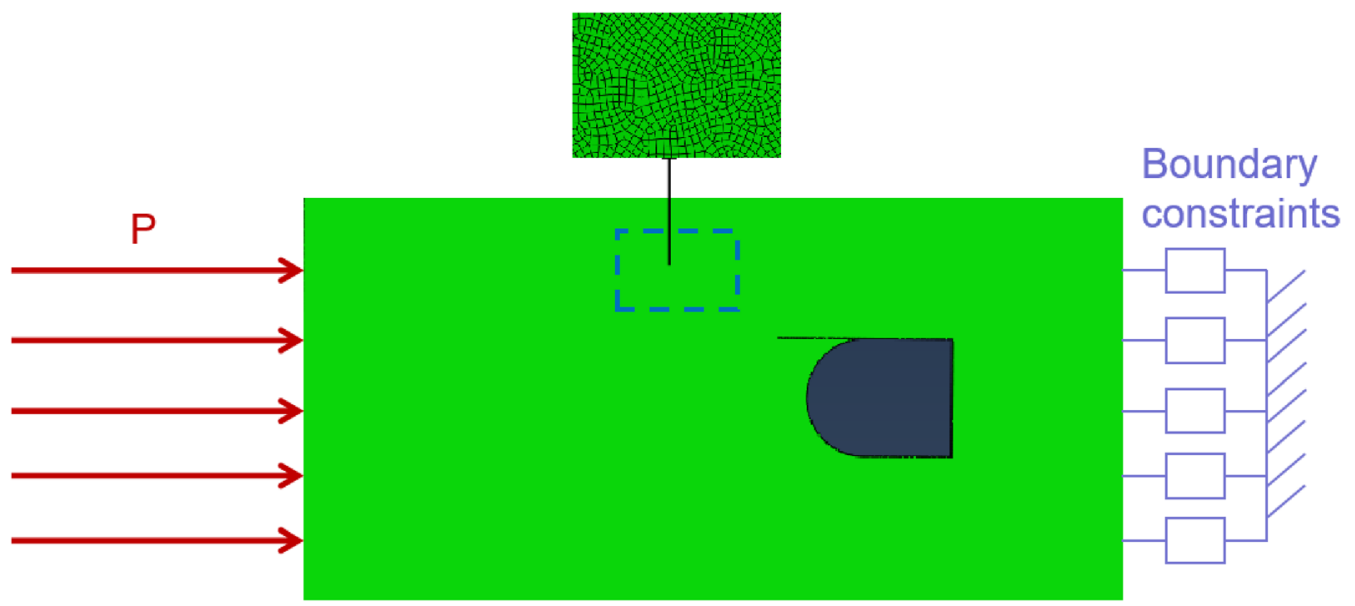

Fig. 16 Typical mesh in ABAQUS

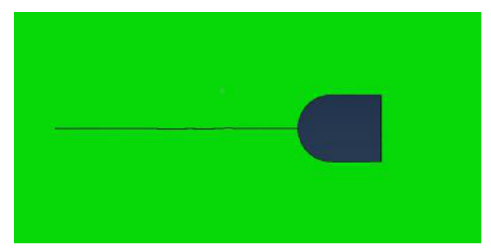

(a) Specimen A

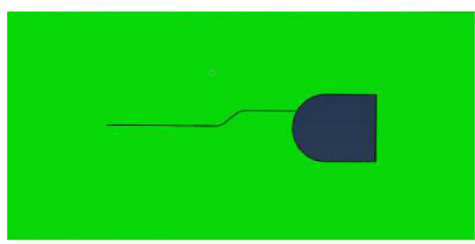

(b) Specimen B

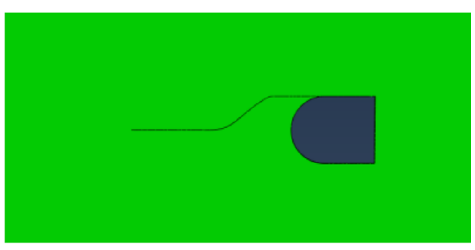

(c) Specimen C

Fig. 17 Simulation of crack propagation for each specimen

With increasing $\alpha$, the radial component of the stress wave decreases gradually, while the tangential component increases gradually. When $\alpha=90^{\circ}$, the radial component of the stress wave is zero, and the crack no longer moves in a curve. Meanwhile, the tangential component reaches its maximum, which is equal to the magnitude of the stress wave at this moment. 


\section{Numerical simulations}

To better verify the crack propagation law of the semicircular-arch roadway under impact, the commercial software ABAQUS was used to simulate the crack fracture process. The extended finite-element method in ABAQUS is used widely to study the deformation and fracture of solid materials under various types of loading.

\subsection{Numerical model of specimen}

In the simulations, it was assumed that the material changed only via crack propagation. To ensure uniform onedimensional loading, an output terminal comprising the bullet and incident rod was used for modeling (the outputterminal load was the same as that in the test). The shear modulus of the bullet and incident rod was $G_{1}=81 \mathrm{GPa}$, their Poisson's ratio was $V_{\mathrm{d} 1}=0.26$, and their material density was $7900 \mathrm{~kg} / \mathrm{m}^{3}$. The bullet model (gray grid) and the incident-bar model (yellow grid) comprised 412 and 1326 elements, respectively, and the grid size was $10 \mathrm{~mm}$ (Fig. 15). The shear modulus of PMMA is $G_{2}=1.28 \mathrm{GPa}$, its Poisson's ratio is $V_{\mathrm{d} 2}=0.31$, and its material density is $1180 \mathrm{~kg} / \mathrm{m}^{3}$. The specimen was modeled by 45706 CPS4R solid elements, and the grid size was $0.05 \mathrm{~mm}$. The grid of a typical specimen is shown in Fig. 16.

\subsection{Simulation results and discussion}

Figure 17 shows the simulated crack propagation trajectory of the specimen after fracture, and the crack propagation tracks of the specimen obtained by test and simulation are compared in Fig. 18. As can be seen, the simulation results for specimen A form a straight line extending along the central axis, whereas the actual test results have a small expansion in the $Y$ direction. The simulation results for specimens $\mathrm{B}$ and $\mathrm{C}$ are roughly the same as the actual test results; however, the simulated expansion path is smoother, while the experimental path fluctuates up and down in a few cases. This is related to the machining accuracy of the test material and the nature of the material itself. In the simulations, it was considered that both ends of the specimen were completely flat and smooth and that the specimen material was completely uniform. However, it is difficult to achieve these conditions in a practical experiment, which is why the actual crack growth path fluctuated up and down in a small range.

\section{Conclusions}

In a semicircular-arch roadway, the conditions for crack propagation after impact by an external load differ depending on the crack position. Therefore, this aspect is
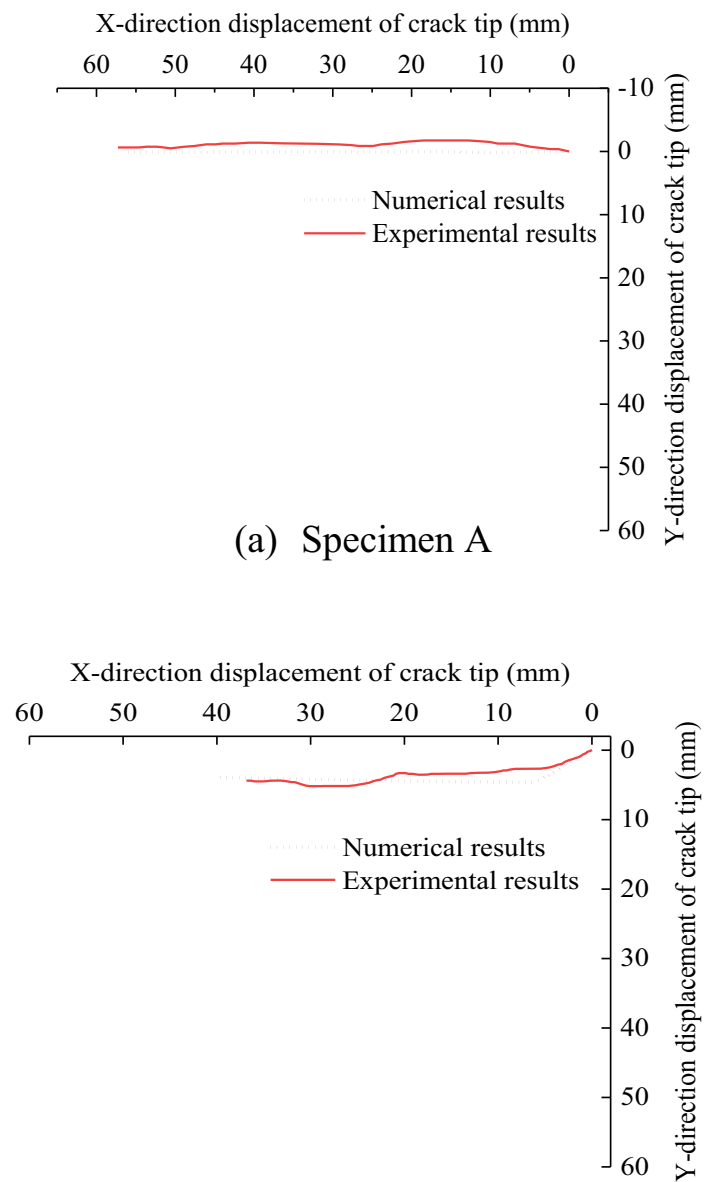

(b) Specimen B

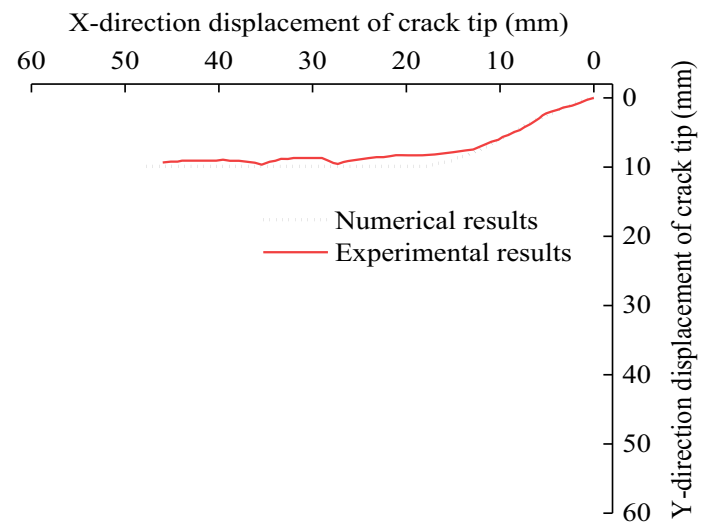

(c) Specimen $\mathrm{C}$

Fig. 18 Comparison of crack paths between simulation and experiment 
very important when studying the impact of defect locations on roadways. The DLDC and SHPB systems described herein can be used to study the propagation of cracks under one-dimensional stress. Combined with the ABAQUS software for numerical simulation, the following conclusions are obtained.

When the pre-fabricated crack is on the central axis, the crack propagation is pure type I. When the pre-fabricated crack is located $5 \mathrm{~mm}$ from the central axis, the crack growth is alternately type I and mixed type I-II. When the pre-fabricated crack is at the edge of the roadway, the crack propagation is the mixed I-II type.

When the pre-fabricated crack is on the central axis, it expands along the central axis after being impacted. When the pre-fabricated crack deviates from the central axis and moves upward, its propagation trajectory is a circular arc. It then moves horizontally when approaching the central axis, but it does not cross the central axis.

When the crack is on the central axis, its displacement in the $X$ direction is the largest. When the pre-fabricated crack is $5 \mathrm{~mm}$ from the central axis, the energy accumulation stage has the shortest time and the initial crack initiation toughness is the lowest. When the pre-fabricated crack is at the edge of the roadway, the peak crack growth velocity $V_{\mathrm{z} \max }$ is the largest. As the pre-fabricated crack shifts upward, its displacement in the $Y$ direction increases.

The extended finite-element method in ABAQUS can better predict the crack propagation after impaction when the semicircular-arch roadway contains pre-fabricated cracks. The simulations results are basically similar to the test results.

Acknowledgements This work was financed by the State Key Development Program for Basic Research of China (2016YFC0600903) and the National Natural Science Foundation of China (51774287).

\section{Declarations}

Conflict of interest There are no conflicts to declare.

Open Access This article is licensed under a Creative Commons Attribution 4.0 International License, which permits use, sharing, adaptation, distribution and reproduction in any medium or format, as long as you give appropriate credit to the original author(s) and the source, provide a link to the Creative Commons licence, and indicate if changes were made. The images or other third party material in this article are included in the article's Creative Commons licence, unless indicated otherwise in a credit line to the material. If material is not included in the article's Creative Commons licence and your intended use is not permitted by statutory regulation or exceeds the permitted use, you will need to obtain permission directly from the copyright holder. To view a copy of this licence, visit http://creativecommons. org/licenses/by/4.0/.

\section{References}

Cheng XY (2019) Damage and failure characteristics of rock similar materials with pre-existing cracks. Int $\mathbf{J}$ Coal Sci Technol 6(4):505-517. https://doi.org/10.1007/s40789-019-0263-4

Goseki R, Ishizone T (2015) Poly (methyl methacrylate) (PMMA). Springer, Berlin, Heidelberg. https://doi.org/10.1007/978-0-38730160-0_8999

Guan DC, Yang ZH (1983) Caustic line method and its application in the determination of stress intensity factor. J Beijing Univ Technol 3:65-77

Guo DM, Liu K, Yang RS et al (2015) Experimental research on the influence of blasting on the inclined crack in the back- blasting side of nearby roadway. J Min Saf Eng 32(1):99-104. https://doi. org/10.13545/j.cnki.jmse.2015.016

Guo DM, Liu K, Hu JX et al (2016) Experimental study on the effect mechanism of the explosion gas on the precrack in the backblasting of adjacent tunnel. J China Coal Soc 41(1):265-270. https://doi.org/10.13225/j.cnki.jccs.2015.1249

Kalthoff JF (1986) The shadow optical method of caustics. Proc Int Sympos Photoelast 9:109-120. https://doi.org/10.1007/978-4431-68039-0_14

Kalthoff JF, Winkler S, Beiner J (1986) Dynamic Stress-intensity factors for arresting cracks in DCB Specimens. Int $J$ Fract 12:317-319. https://doi.org/10.1007/BF00036990

Karimzada T, Maigre H (2000) Modelisation of dynamic crack propagation criteria. J Phys IV 1997:13-18. https://doi.org/10. 1051/jp4:2000977

Li SC, Yang L, Li MT et al (2009) Influences of 3dinternal crack dip angle on tensile mechanical properties and fracture features of rock-like material. Chin J Rock Mech Eng 28(2):281-289. https://doi.org/10.1007/978-3-540-85168-452

Li JC, Li NN, Li HB et al (2017) An SHPB test study on wave propagation across rock masses with different contact area ratios of joint. Int J Impact Eng 105:109-116. https://doi.org/10.1016/j. ijimpeng.2016.12.011

Li CX, Zhang YT, An C (2020) Study on the dynamic propagation and numerical simulation of mode I and mixed mode I-II cracks in PMMA specimens with unilateral semicircular holes. J Min Sci Technol 5:490-501

Liu W, Yao XF, Yang RS et al (2020) Multi-crack propagation in PMMA plates under dynamic out-of-plane impact. Optics Lasers Eng 124:105849. https://doi.org/10.1016/j.optlaseng.2019. 105849

Manogg P (1964) Anwendung der Schattenoptik zur Untersuchung des Zerreissvorgangs von Platten. University of Freiburg, West Germany

Pan WD, Wang X, Liu QM et al (2019) Non-parallel double-crack propagation in rock-like materials under uniaxial compression. Int J Coal Sci Technol 6(3):372-387. https://doi.org/10.1007/ s40789-019-0255-4

Rosakis AJ (1980) Analysis of the optical method of caustics for dynamic crack propagation. Eng Fract Mech 13(2):331-347. https://doi.org/10.1016/0013-7944(80)90063-6

Rossmanith HP, Daehnke A, Nasmillner R et al (1997) Fracture mechanics applications to drilling and blasting. Fatigue Fract Eng Mater Struct 20(11):1617-1636. https://doi.org/10.1111/j. 1460-2695.1997.tb01515.x

Sih GC (1981) Experimental evaluation of stress concentration and intensity factors. Martinus Nijhoff Publishers, Dordrech. https:// doi.org/10.1007/978-94-009-8337-3

Theocaris PS (1972) Reflected shadow method for the study of constrained zones in cracked plates. Appl Opt 10:240-247. https://doi.org/10.1364/AO.10.002240 
Wang YB, Yang RS, Zhao GF (2017a) Influence of empty hole on crack running in PMMA plate under dynamic loading. Polym Test 58:70-85. https://doi.org/10.1016/j.polymertesting.2016.11. 020

Wang YB, Yang RS, Zhao GF (2017b) Influence of empty hole on crack running in PM-MA plate under dynamic loading. Polym Test 58:70-85. https://doi.org/10.1016/j.polymertesting.2016.11. 020

Wu X, Yang HT (1984) Application of caustic line method in fracture mechanics (determination of stress intensity factor). J Solid Mech 2:299-308

Xu P, Chen C, Guo Y et al (2019) Experimental study on crack propagation of slit charge blasting in media with vertical bedding plane. J Min Sci Technol 4(6):498-505. https://doi.org/10. 19606/j.cnki.jmst.2019.06.004

Yang LY, Yang RS, Xu P (2013) Caustics method combines with laser and digital high-speed camera and its applications. J China Univ Min Technol 2:31-37. https://doi.org/10.1002/jcla.21600

Yang RS, Wang YB, Hou LD et al (2014) DLDC Experiment on crack propagation in defective medium under impact loading. Chin J Rock Mech Eng 33(10):1971-1976. https://doi.org/10. 13722/j.cnki.jrme.2014.10.004

Yang RS, Xu P, Yue ZW (2016) Dynamic fracture analysis of crackdefect interaction for mode I running crack using digital dynamic caustics method. Eng Fract Mech 161:63-75. https://doi.org/10. 1016/j.engfracmech.2016.04.042

Yang RS, Ding CX, Yang LY et al (2018) Hole defects affect the dynamic fracture behavior of nearby running cracks. Shock Vib 2018:1-8. https://doi.org/10.1155/2018/5894356
Yao XF, Jin GC, Arakawa K, Takahashi K (2002) Experimental studies on dynamic fracture behavior of thin plates with parallel single edge cracks. Polym Test 21(8):933-940. https://doi.org/ 10.1016/S0142-9418(02)00037-5

Yao XF, Xu W, Xu MQ et al (2003) Experimental study of dynamic fracture behavior of PMMA with overlapping offset-parallel cracks. Polym Test 22(6):663-670. https://doi.org/10.1016/ S0142-9418(02)00173-3

Yue ZW, Yang RS, Sun ZH et al (2010) Simulation experiment of rock fracture containing inclined edge crack under impact load. J China Coal Soc 35(9):1456-1460. https://doi.org/10.13225/j. cnki.jccs.2010.09.001

Zhou L, Zhu ZM, Dong YQ et al (2019a) Study of the fracture behavior of mode I and mixed mode I/II cracks in tunnel under impact loads. Tunn Undergr Space Technol 84(11):11-21. https://doi.org/10.1016/j.tust.2018.10.018

Zhou L, Zhu ZM, Dong YQ et al (2019b) The influence of impacting orientations on the failure modes of cracked tunnel. Int J Impact Eng 125:134-142. https://doi.org/10.1016/j.ijimpeng.2018.11. 010

Zhou L, Zhu ZM, Dong YQ et al (2020) Investigation of dynamic fracture properties of multi-crack tunnel samples under impact loads. Theoret Appl Fract Mech 109:102733. https://doi.org/10. 1016/j.tafmec.2020.102733

Zhuang X, Chun J, Zhu H (2014) A comparative study on unfilled and filled crack propagation for rock-like brittle material. Theoret Appl Fract Mech 72:110-120. https://doi.org/10.1016/j.tafmec. 2014.04.004 